\section{Biomechanical Evaluation of}

Lumbosacral Segments Response

under Physiological Functions:

Finite Element Analysis

\author{
Moнammed BENDOUKHA - Laboratory of Numerical and Experimental Modeling of Mechanical \\ Phenomena, Department of Mechanical Engineering, University Abd El Hamid IbnBadis \\ - bendoukham@yahoo.fr \\ MustaPhA MOSBAH - Laboratory of Numerical and Experimental Modeling of Mechanical Phenomena, \\ Department of Mechanical Engineering, University Abd El Hamid IbnBadis
}

Érkezett: 2017. 10. 26. " Received: 26. 10. 2017. - https://doi.org/10.14382/epitoanyag-jsbcm.2017.22

\begin{abstract}
The basic key in the process of our validation may be stated in the development of computational analogues of the spinal morphologies by the creation of sophisticated 3-dimensional Finite Element (FE) model of an intact ligamentous L1-S1 motion segment that matches the real biomechanical behavior of the human lumbosacral spine and for this purpose, the curves were found to be non-linear and the Ranges of Motion (ROM) results were found to compare favorably with reported values from in vivo and in vitro studies as documented in experiments conducted on human cadavers [1, 2]. Therefore, this FE-model can be used to investigate the stress and strain distributions in the L1-S1components, especially the discs under physiological functions such as heavy and daily carrying tasks it has the possibility of representing the realities with a much higher degree of fidelity.
\end{abstract}

Keywords: Finite Element, lumbar spine behavior, ranges of motion, in vivo, in vitro

Kulcsszavak: végeselem, ágyéki gerinc viselkedése, mozgástartomány, in vivo, in vitro

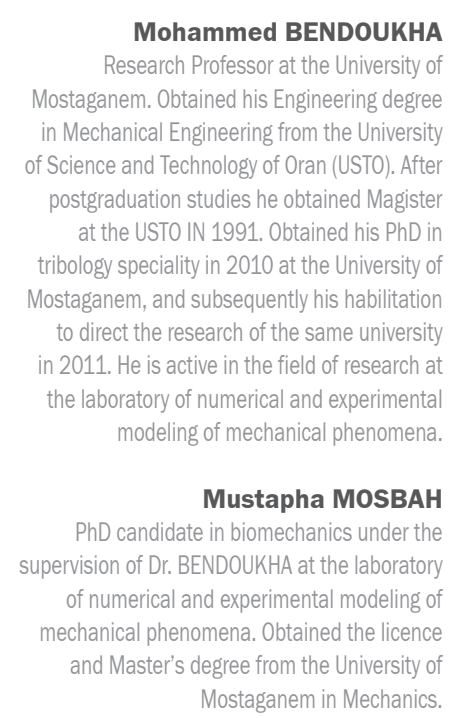

\section{Introduction}

The aim of this work is to make an accurate computational FE-model to simulate the biomechanical response of the human lumbar spine under physiological functions. Its success at simulation is not insured but must be tried out by suitable validation to insure the accuracy of any FE-model. The model is conceived as regards validated if, in circumscribed number of offices, its predicted behavior comes close to the experimental results. It is then assumed that the model may now be exercised to predict behavior of the structure in other situations by knowledge of regular spinal movements [3], The lumbar region is a recurring set of spinal disorders $[4,5]$. Clinical studies have testified that abnormal intervertebral motions occur in some patients who have low-back pain and the utmost proportion (about 90\%) of spinal disorders is located in the lumbar spine segment [6].

While, in the absence of pathological disease, regular daily activities, lifting stationary work postures, heavy physical work and vibrations are factors that contribute to low back disorders $[7,8]$. Usually, orthopedic treatment is essentially based on the experience of the surgeon who predicts the best solution for each patient. Using mathematical models and computer simulations could hypothetically be a key tool that supports clinical decisions in order to predict the presence and evolution of spine pathologies, for preoperative planning and implant design. $[9,10,11]$. The present work is concentrates on the analysis of the lumbar spine with the objective of studying of the influence and the roles that the different components of the spine play on its biomechanical response, in particular the presence of an injury in the intervertebral disc (IVD).
In order to understand the whole lumbosacral segments response under physiological conditions, the complete threedimensional elastic physical properties of the lumbar spine were precisely documented, then, (L1-S1) rachis FE-model was built and their mechanical responses under static loading were predicted. [11, 12].

Pure moments of flexion-extension, in lateral axial torque, and in lateral, lateral bending were applied, and three-dimensional intervertebral motions were determined. The motions were presented in the form of a set of six load-displacement curves, quantifying the intervertebral rotations and translations. The current model should preserve the anatomical details required to simulate the biomechanical response, including tissue material properties appropriate for treatment of spinal disorders, and be validated in relevant loading scenarios.

\section{Methods and materials}

The main procedure is employed hierarchical approaches to develop a biomedical validated computational model of the lumbar spine to investigate the spinal disorders and diseases $[11,13]$.

An Osseo-ligaments FE-model of the L1-S1 levels was built and validated through comparison with literature data. An extended description of the model and its adaptation for the present study are outlined below in this study. The developed lumbar spine FE-model was created based on anatomically accurate geometries and was modeled based on the epidemiology of injuries and disease due to the literature [1, 13, 11]. FE Analyses were performed using a 3-Dimensional 
nonlinear model of the spine arraying from L1 to S1, created following multiple processes (Fig. 2).

The global geometry was derived from a CT scan based on the reconstitution of the L5/S1 FSU Data taken from a male cadaver what did not have any trauma or pathology that affect bone quality and integrity of vertebral bodies, then translated to patch iges model then to a simplified solid model using Power surfacing (Solid works 2013). (Fig. 1)
A)

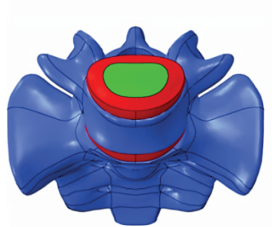

B)

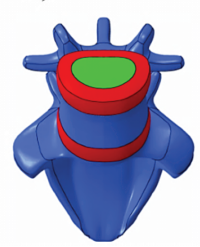

C)

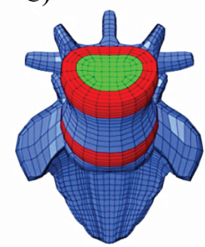

Fig. 1. A) Realistic L5/S1 Geometric Model, B) Simplified Power Surfacing Geometric Model, C) Generated Meshed Model using Ansys

1. ábra A) Realisztikus L5/S1 geometriai modell, B) egyszerüsített hatványfelület geometriai modell, C) Ansys szoftverrel generált modell hálója

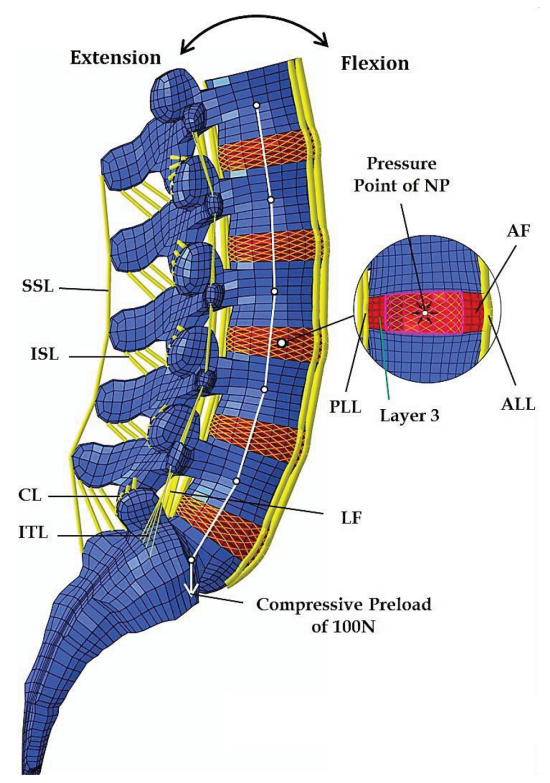

Fig. 2. Finite element model of the lumbosacral spine L1-S1 and intra discal pressure point

2. ábra Lumboszakrális L1-S1 gerinc szakasz végeselemes modellje és intradiszkális nyomáspont

This geometrical simplification allowed the full optimization of an accurate three dimensional model. The reconstructed Solid model of L5/S1 was derived from a commercial model of the spine (Zygote Media Group - American Fork, UT, USA). The geometry of the vertebra and the intervertebral disc was approximated to match the realistic model of normal cadaveric lumbar segments. The model of a Lumbar Spine was developed using ANSYS revision 15.0 (ANSYS Inc., Houston, PA, USA). However, fully automated hexahedral mesh generation is not available for complex geometric entities such as the human lumbar spine. Utilizing hexahedral elements to effectively model the complexly shaped lumbar spine is not trivial and requires a substantial amount of work to subdivide the geometry in preparation for mesh generation. This meshing is desirable for FE analysis due to the nature of their shape function and ability to handle large deformations without creating numerical instabilities.

Concerning the parametric meshing, the developed spinal mesh was symmetrically modeled across the midsagittal plane as adopted in the literature [15], the mesh density and geometry was defined to represent the key passive anatomical features: cortical and cancellous bone; endplates; posterior elements of the vertebrae; annulus fibrosis and nucleus pulposus; articular cartilage; synovial fluid of the facet joint [11, 12]. 8-noded solid element (C3D8) were used to define The cancellous bone and posterior elements of the vertebrae and articular cartilage of the facet joints ,the cortical bone and endplates of the vertebrae and elsewhere using hexahedral element based on hybrid formulation for hyperelastic structure for the Annulus Pulposus (AP). Cortical bone and endplates of the vertebrae modeled using 8-noded brick elements with 0.635 mm thickness. $[14,15]$.The commercial FE package Abaqus, version 14.1 was used to formulate the FE-model.

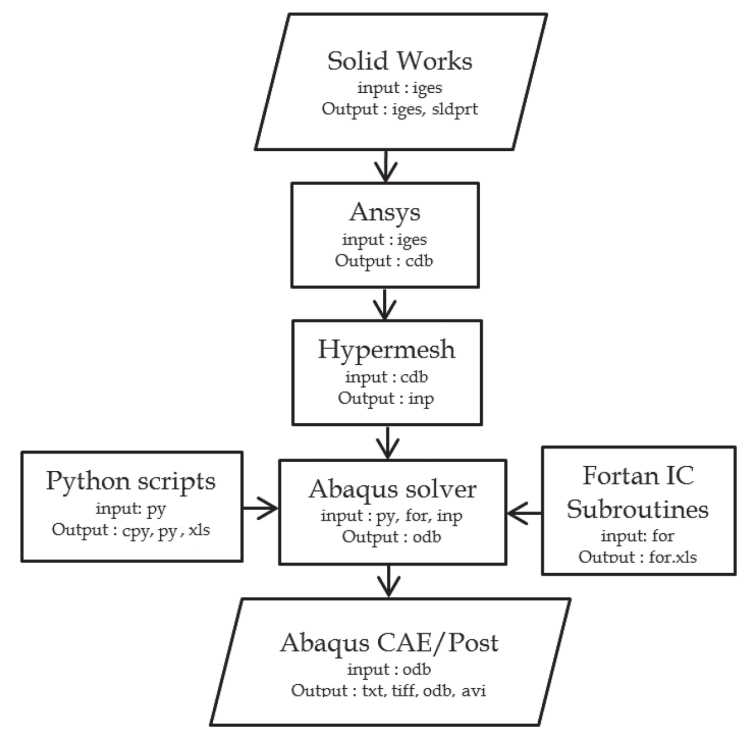

Fig. 3. Finite Element Model, Formulation Workflow Chart

3. ábra Végeselemes modell generálási folyamatábra

\section{Numerical investigation}

\subsection{L1-S1 motion segment validation}

\subsubsection{Boundary and Loading Conditions}

A well-defined Hybrid protocol was used to study the lumbosacral spine behavior. This key issue analysis reestablishes to principle applied load on the motion segments of pure momentum increasing incrementally from zero to $10 \mathrm{~N} . \mathrm{m}(2.5$, 5, 7.5, $10 \mathrm{~N} . \mathrm{m})$. Compressive follower preload of $100 \mathrm{~N}$ was applied in all modalities to the intact lumbar spine model in the follower load path direction, settled as suggested thereby allowing the axial load to follow the motion of the spine [9]. The Follower load was applied to the center of the vertebra through a Reference Node Constrained to the vertebral body nodes using Coupling Constraints Elements (CCE). The resulting FE-model was positioned in static Momentum Loads to match the experiment. Homogeneous Dirichlet boundary conditions were applied to all bottom side nodes, not involved 
L1-L2
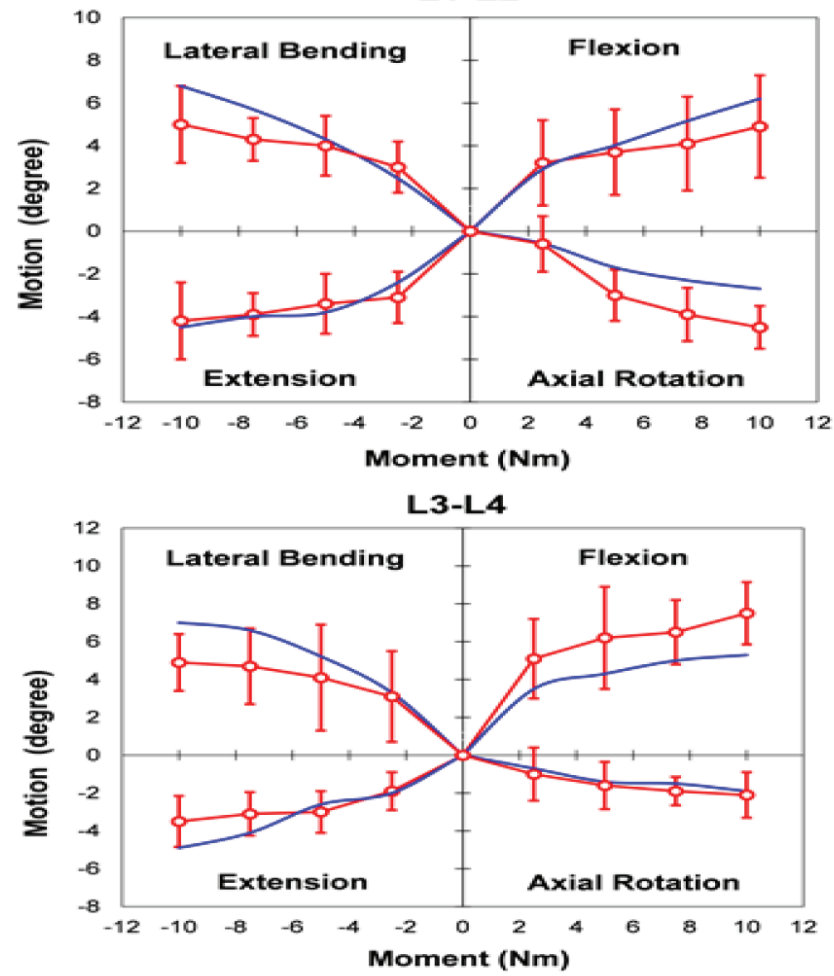

EXP (Panjabi) - FEM
L2-L3
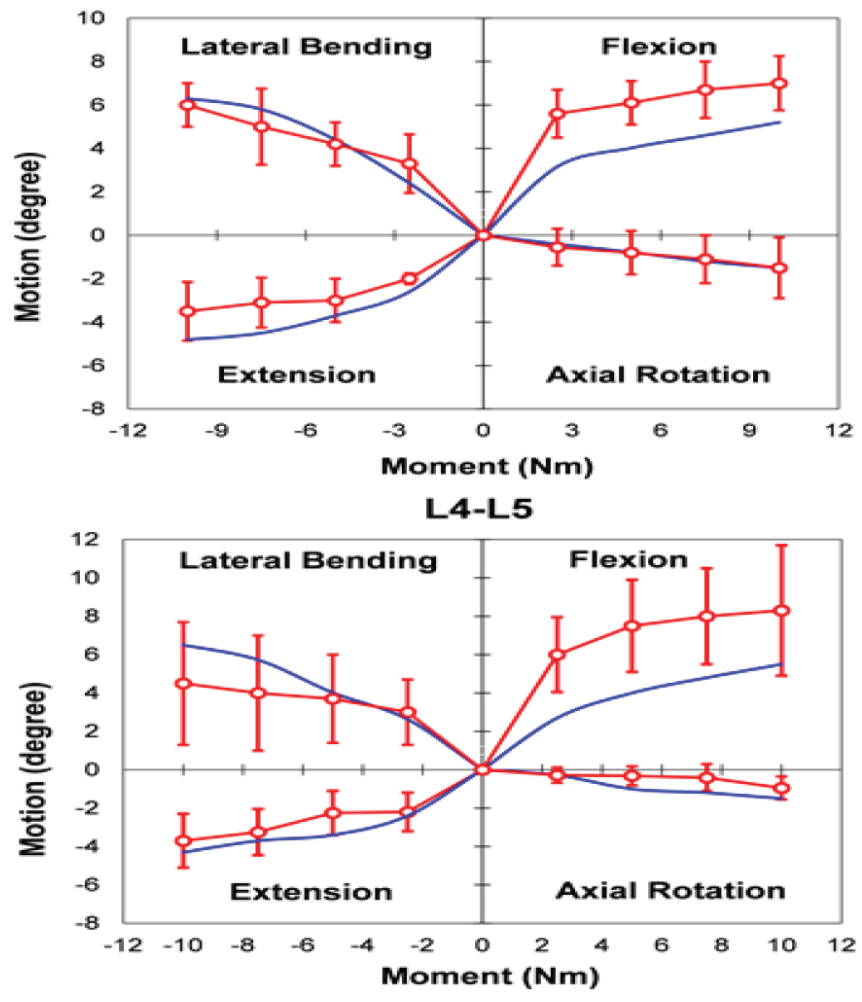

L5-S1

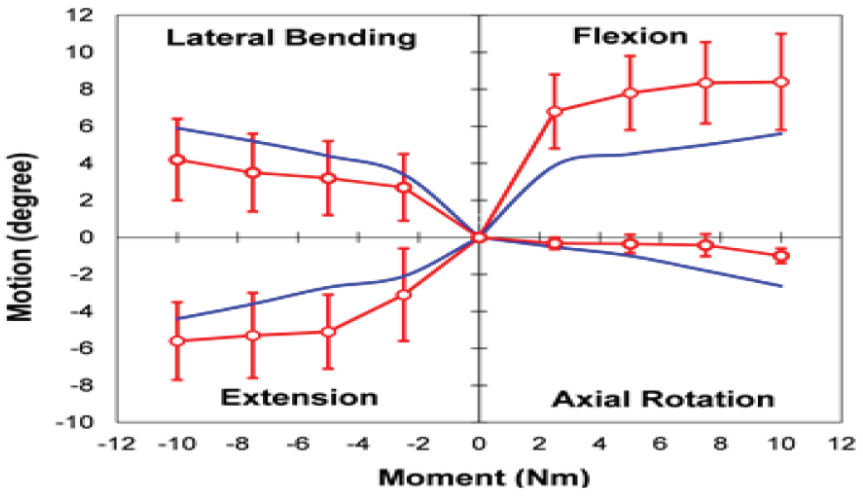

Fig. 4. Comparison between predicted intervertebral rotations results in different spinal levels for the loading cases flexion, extension, lateral bending, and axial rotation 4. ábra Porckorong elmozdulások összehasonlítása a gerinc különböző szintjein; hajlítás, megnyúlás, keresztirányú hajlítás, tengelyirányú elfordulás

in the motion procedure. The interpedicular displacement was predicted for the intact model in all directions, comparing with that of previous experimental studies [2]. Introduce the generated lumbar spine model not only allows personalized biomechanical analysis, but it also offers detailed geometric data to simplify simulation to mimic the realistic Lumbar spine. Knowledge of the normal motions of the whole lumbar spine and lumbosacral joint is important for evaluating clinical pathologic conditions.

\subsubsection{Results}

The results display a greater no-linearity of the spine response. Under load combination, the ROM of most of the dedicated FSU level, respectively from $L 1$ to $S 1$ is within the range of in vitro measurements as shown in Fig. 4, except a reduction of the predicted $\mathrm{ROM}$ in flexion, where the mobility is smaller than what is expected (L2-L3, L4-L5, L5-S1), taking into account in vitro conditions. In lateral bending and in axial rotation, the movement amplitudes are close to those found in the literature measurements as shown in Fig. 4. In particular, in extension, such as for the other movements, ROM are within the range of movements performed by the experimental ones especially for L1-L2, L2-L3, L3-L4 segments. Except for the segment L5-S which performs a little lower extension than in vitro measure, at L1-L2 level for extension in which we obtain a value of $4.2^{\circ}$ against the experimental value of $4^{\circ}$. The numerical model in extension for the L4-L5 segment shows a deviation of $0.5^{\circ}$ against the calculated experimental values.

The curves are similar with slightly higher rotation angles for the model in Axial Rotation for L4-L5 and L5/S1.

The segment L2-L3, L4-L5 shows the best results with an error of $0.1^{\circ}$ and for the L3-L4 segment with a deviation of 0.2 between the FE-model and experimental. The maximum 
flexion moment ROM of the segments L1-L2 is higher than for the other segments, the maximum rotation value has little variation between upper $\left(-6.1^{\circ}\right.$ for L1-L2 level) and lower $\left(-5.8^{\circ}\right.$ for L4-S1) segments. The FE-models are obtained at the L2-L3 level a deviation of $0.2^{\circ}$ in the lateral bending and represent a deviation of $0.8^{\circ}$ for the Axial Rotation of L5-S1.

\section{Discussion}

Validation of Any new finite element model should be observed the correlation between FE predictions and in vitro data to correctly reproduce key aspects of in vitro response of the lumbar spine. The Rotations-Displacement curves from the generated FE-model shows good accuracy of the experimental kinematics measurements. This FE-model of a human L1-S1 motion segment was used to explore the effect of daily physiological loads on the overall behavior of the lumbar spine. The ROM configuration of the model matches the experiment well for the overall L1-S1 endpoints. The loading applied to the model was formulated to simulate the observed physiological functions. The finite element modeling has long been used in biomechanical studies for research concerning clinical pathologies of the lumbar spine as well as for predicting the biomechanical characteristics. The lumbar spine model was developed to investigate the disc behavior and the whole L1-S1 functions under physiological conditions. The focus of this study was a validation of the theme shing, and FEmodel generation procedure, with the latter step comprising construction and of the lumbar model L1-S1. This model generation step requires a substantial time commitment.

The geometric assumptions made in the development of the model were intended to allow an anatomically detailed representation of the Posterior-Anterior column. The computational results presented in this study represent an attempt to explore the role of passive spinal structures in generating rotations displacements accompanying primary spinal motions. We presented a finite element model for an isotropic with homogenous properties of the IVD, and the mechanical properties such as the non-linear behavior of the spinal ligaments. Healthy osseo ligamentous lumbosacral spine with all intact ligaments and a hydrostatic nucleus pulposus (1) The structure of the vertebral body was assumed as (2) The loading conditions were not truly physiological, because of the lack of the mechanical effects of muscular contraction forces which change with upper trunk position $[3,14]$.

\section{Limitations of the FE analysis}

As with all finite element model research, there are some inherent limitations of the models used: To realize a better resolution and results, it might be essential to refine the mesh which steer more anatomic details, require significant sensitivity analysis with more elements and nodes, including more degrees of freedom. These additions would have inconveniently increased the computation time and necessitate expense of computation power. The geometry of the IVD was based on realistic $3 \mathrm{~d}$ model reconstituted from slice imaging scans but with limited accuracy. The variation in geometric parameters, such as disc height, cross-sectional area of the intervertebral disc, size and position of the nucleus fiber orientation, or the number of fiber layers, can affect the mechanical behavior of the intervertebral disc and the whole lumbar functions $[5,6]$. The procedure that joins FE models with different geometries might lead to remarkable different results and the modification in geometries and conditions of soft tissues in the finite element model introduced in previous biomechanical studies may alter the reported ROM.

\section{Conclusions}

We have presented a FE-model of the lumbar spine and have described how the model has been constructed based on the anatomical and computational features of the spine segments in the sake of computational efficiency. The intact model has been validated in good correlation with the literature where simulations have been achieved for physiological ROM (Fig. 5). This study presents a first step in the validation process of the FE-model for the individual human lumbar spine. Out of a number of model features analyzed computationally, reasonable approximations of the experimental data are provided by this model. Future work will focus on better understanding the sensitivity of FE predictions to variations in material properties associated with factors such as degeneration and the use of an optimization method based on differential evolution to calibrate the FE-model the whole lumbar spine. The approach for selecting such material properties involves calibrating the model by choosing the properties that produce the best compatibility with the in vivo and in vitro mechanical response of the lumbar spine. Whether, these approximations will be expressed terms of a FE-model for the intact L1-S1 finite element formulation, and the developed model could be considered as a valuable tool for the investigation of mechanical analysis of the lumbar segment in the perspective promote of pre and postoperative clinical analysis.

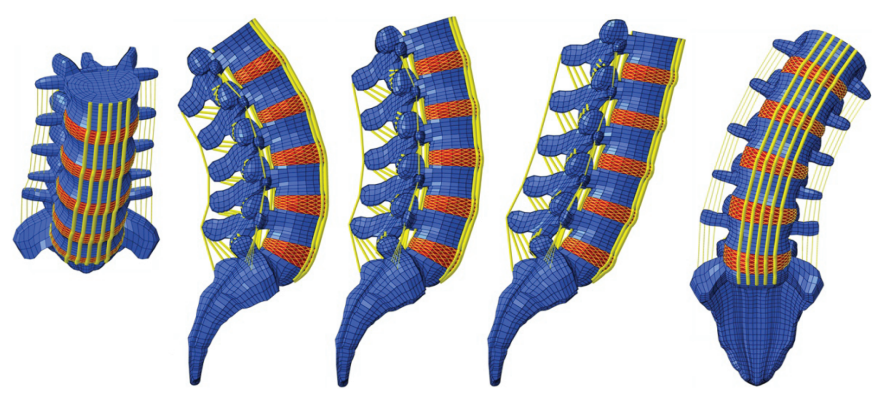

Fig. 5. Simulation of different Physiological Functions: $10 \mathrm{Nm}+100 \mathrm{~N}$

5. ábra Szimulációs eredmények különbözö fiziológiai hatásokra: $10 \mathrm{Nm}+100 \mathrm{~N}$

\section{References}

[1] Panjabi M. M. - Krag M. H. - Chung T. Q. (1984): Effects of disc injury on mechanical behavior of the human spine. Spine, Vol. 9, pp. 707-713.

[2] Panjabi M. M. - Oxland T. R. - Yamamoto I. - Crisco J. J. (1994): Mechanical behavior of the human lumbar and lumbosacral spine as shown by three-dimensional load-displacement curves, The Journal of Bone and Joint Surgery, Series A, Vol. 76, pp. 413-424.

[3] Moramarco, V. - Palomar, A. P. - Pappalettere, C. - Doblaré, M. (2010): An accurate validation of a computational model of human lumbosacral segment, Journal of Biomechanics, Vol. 43, No, 2, pp. 334-342. 
[4] Goel, V. K. - Monroe, B. T. - Gilbertson, L. G. - Brinckmann, P. (1995a): Interlaminar shear stresses and laminae separation in the disc. Finite element analysis of the L3-L4 motion segment subjected to axial compressive loads. Spine, Vol. 20, No. 6, pp. 689-698.

[5] Tyndyk M. A. - Barron V. - Mchugh P. E. - O’Mahoney D. (2007): Generation of a finite element model of the thoracolumbar spine, Acta of Bioengineering and Biomechanics, Vol. 9, pp. 35-46.

[6] Luoma K. - Riihimaki H. - Luukkonen R. et al. (2000): Low Back Pain in Relation to Lumbar Disc Degeneration. Spine, Vol. 25, No. 4, pp. 487-492.

[7] Natarajan R. N. - Andersson G. B. (1999): The influence of lumbar disc height and cross-sectional area on the mechanical response of the disc to physiologic loading. Spine, Vol. 24, pp. 1873-1881.

[8] Sheehan J. M. - C. I. Shaffrey - J. A. Jane (2001): Degenerative lumbar stenosis: The neurosurgical perspective. Clinical Orthopaedics \& Related Research, Vol. 384, pp. 61-74.

[9] Patwardhan, A. G. et al. (1999): A Follower Load Increases the LoadCarrying Capacity of the Lumbar Spine in Compression. Spine, Vol. 24, No. 10, p. 1003.

[10] Zhong, Z. C. - Wei, S. H. - Wang, J. P. - Feng, C. K. - Chen, C. S. - Yu, C. H. (2006): Finite element analysis of the lumbar spine with a new cage using a topology optimization method, Medical Engineering and Physics, Vol. 28, No. 1, pp. 90-98.

[11] Rohlmann A. - Zander T. - Schmidt H. - Wilke H-J. - Bergmann G. (2006): Analysis of the influence of disc degeneration on the mechanicalbehavior of a lumbar motion segment using the finite element method. Journal of Biomechanics, Vol. 39, pp. 2484-2490.

https://doi.org/10.1016/j.jbiomech.2005.07.026
[12] Schmidt H. - Heuer F. - Simon U. - Kettler A. - Rohlmann A. - Claes L. et al. (2006): Application of a new calibration method for a threedimensional finite element model of a human lumbar annulus fibrosus. Clinical Biomechanics, Vol. 21, pp. 337-344.

[13] Park W. M. - Kim K. Y. - Kim H. (2013): Effects of degenerated intervertebral discs on intersegmental rotations, intradiscal pressures, and facet joint forces of the whole lumbar spine. Computers in Biology and Medicine, Vol. 43, pp. 1234-1240.

[14] Cao K. D. - Grimm M. J. - Yang K. H. (2001): Load sharing within a human lumbar vertebral body using the finite element method. Spine, Vol. 26, pp. 253-260.

[15] Moumene M. - Geisler F. H. (2007): Comparison of biomechanical function at ideal and varied surgical placement for two lumbar artificial disc implant designs: mobile-core versus fixed-core. Spine, Vol. 32, pp. 1840-1851. https://doi.org/10.1097/BRS.0b013e31811ec29c

[16] Langrana N. A. - Rodríguez J. (1995): Role of ligaments and facets in lumbar spinal stability. Spine, Vol. 20, pp. 887-900.

[17] Lu Y. M. - Hutton W. C. - Gharpuray V. M. (1996): Do bending, twisting, and diurnal fluid changes in the disc affect the propensity to prolapse? A viscoelastic finite element model. Spine, Vol. 21, pp. 2570-2579.

\section{$\underline{\text { Ref.: }}$}

Bendoukha, Mohammed - Mosbah, Mustapha: Biomechanical Evaluation of Lumbosacral Segments Response under Physiological Functions: Finite Element Analysis

Építỏanyag - Journal of Silicate Based and Composite Materials, Vol. 69, No. 3 (2017), 122-126. p. https://doi.org/10.14382/epitoanyag-jsbcm.2017.22

The next European Fluid Mechanics Conference EFMC12 will take place in Vienna at TU Wien from September 9 to September 13, 2018.

The EFMC is organized biennially under the auspices of the European Mechanics Society EUROMECH and covers all fields of fluid mechanics. Since the inaugural meeting in Cambridge 1991 the EFMC has evolved to the main fluid mechanics conference in Europe. It provides the opportunity to meet and discuss with the leading scientists in the field.

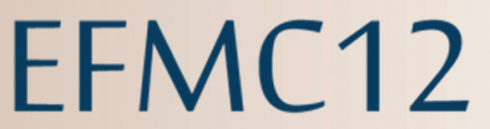

The 12th European

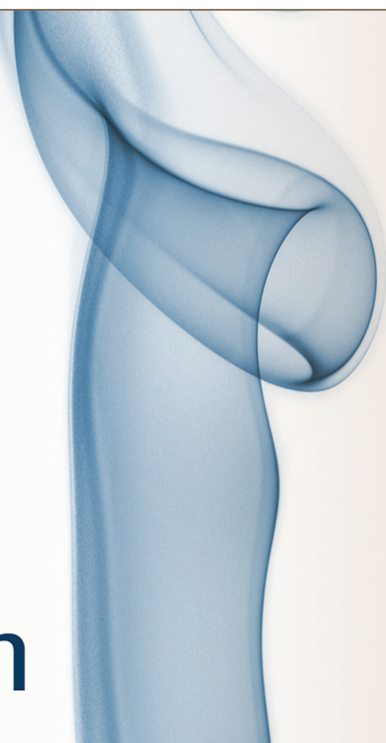

Fluid Mechanics Conference

\section{September 9-13, 2018, TU Wien, Vienna}

\section{http://efmc12.conf.tuwien.ac.at}
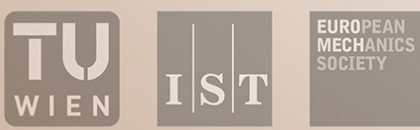